\title{
H. Adlai Murdoch, Anne Donadey (a cura di), Postcolonial Theory and Francophone Literary Studies
}

\section{Alessandro Corio}

\section{Q OpenEdition}

12 Journals

\section{Edizione digitale}

URL: https://journals.openedition.org/studifrancesi/26857

DOI: 10.4000/studifrancesi.26857

ISSN: 2421-5856

\section{Editore}

Rosenberg \& Sellier

\section{Edizione cartacea}

Data di pubblicazione: 1 avril 2007

Paginazione: 215-216

ISSN: 0039-2944

\section{Notizia bibliografica digitale}

Alessandro Corio, «H. Adlai Murdoch, Anne Donadey (a cura di), Postcolonial Theory and Francophone Literary Studies», Studi Francesi [Online], 151 (LI | I) | 2007, online dal 30 novembre 2015, consultato il 23 novembre 2021. URL: http://journals.openedition.org/studifrancesi/26857 ; DOI: https://doi.org/ $10.4000 /$ studifrancesi.26857

Questo documento è stato generato automaticamente il 23 novembre 2021.

\section{(c)}

Studi Francesi è distribuita con Licenza Creative Commons Attribuzione - Non commerciale - Non opere derivate 4.0 Internazionale. 


\title{
H. Adlai Murdoch, Anne Donadey (a cura di), Postcolonial Theory and Francophone Literary Studies
}

\author{
Alessandro Corio
}

\section{NOTIZIA}

H. ADLAI MURDOCH, ANNE DONADEY (a cura di), Postcolonial Theory and Francophone Literary

Studies, Gainesville: University Press of Florida, 2005, pp. 271.

1 Questa corposa ed importante raccolta di saggi si presenta come un approccio comparativo ed oltremodo eterogeneo all'intersezione - che solo negli ultimi anni ha cominciato a prendere piede quasi esclusivamente, con alcune rilevanti eccezioni, nell'ambito della produzione anglofona - tra teorie postcoloniali e studi francofoni. I numerosi ed importanti autori e i curatori di questo volume cercano di tracciare una mappa che renda conto delle fertili contaminazioni e disseminazioni che possono nascere da quest'incontro e dal rispettivo decentramento dei due orientamenti critici. Entrambi i campi, infatti, si sono recentemente focalizzati su una serie di elementi e di temi comuni: dalla diaspora all'ibridità, dal nazionalismo postcoloniale al transnazionalismo, dalle tematiche del genere e della razza al multilinguismo, all'esigenza di riscrivere la storia coloniale dal punto di vista dei "subalterni". I lavori di celebri scrittori francofoni come Aimé Césaire, Frantz Fanon e Albert Memmi hanno anticipato ad un livello significativo gran parte delle istanze politiche e critiche fatte proprie dai postcolonialisti a partire dagli anni Ottanta. Nonostante queste premesse, una sorta di reciproca diffidenza e di chiusura in ambiti accademici e linguistici specifici e separati ha tenuto "a distanza di sicurezza" questi due campi, evitando così una rielaborazione teoretica e critica che presenta indubbiamente feconde potenzialità innovative. Gli anni più recenti hanno però segnato una significativa inversione di tendenza di cui è testimone una produzione bibliografica - che va arricchendosi di anno in anno e che propone continuamente nuove e stimolanti chiavi di lettura - nella 
quale spiccano i nomi di grandi critici: Gayatri Spivak, Michael Dash, Françoise Lionnet, Robert Young, Celia Britton, Chris Bongie e Jean-Marc Moura. Tra gli studi più recenti e significativi degli ultimi anni, ci limitiamo a citare l'importante saggio di Celia Britton, Édouard Glissant and Postcolonial Theory: Strategies of Language and Resistance (Charlottesville: University of Virginia Press, 1999) e l'antologia critica, curata da David Murphy e Charles Forsdick, Francophone Postcolonial Studies: A Critical Introduction (London: Edward Arnold, 2003).

2 Le due prospettive critiche nascono da una decentralizzazione progressiva di settori accademici caratterizzati in precedenza da un'impostazione che oggi potremmo definire "etnocentrica" ed "imperialista": i dipartimenti di Letteratura Francese, che vedevano le letterature in lingua francese delle (ex-)colonie come semplici appendici minori della letteratura esagonale, e i dipartimenti dei Commonwealth Studies, anch'essi caratterizzati da un'impostazione colonialista ed etno-universalista. D'altra parte, tanto gli studi francofoni attuali che gli studi postcoloniali, non sono scevri da tendenze omogeneizzanti nei confronti dei loro rispettivi oggetti di studio, rischiando di sminuire e soffocare il potenziale liberatorio delle contro-narrative di cui si occupano per mezzo di concettualizzazioni onnicomprensive che rispecchiano e riproducono il potere neo-coloniale delle nuove istituzioni del capitalismo globale. Questo avviene, in forme diverse, ma per certi versi affini, tanto nel campo degli studi postcoloniali che in quello della francofonia, seminando di paradossi e di trappole il loro rispettivo valore epistemologico ed euristico. Proprio per questo è necessaria una feconda e critica interazione tra i due settori, una reciproca "decolonizzazione" per mezzo di un approccio "comparativo" ed "interdisciplinare", come affermano i curatori nell'Introduzione al volume, significativamente intitolata "Productive Intersections": «It should be clear that we are arguing for transnational intersections among fields that have a natural affinity but are still too often separated by disciplinary and linguistic barriers» (p. 5).

3 Il volume è suddiviso in quattro sezioni, ognuna delle quali presenta una "sottocategoria" degli studi francofoni cercando di "illuminarla" e di "interrogarla" da una prospettiva postcoloniale. La prima sezione, intitolata "Rethinking Theoretical Beginnings", volge uno sguardo all'indietro, oltre l'apparizione, nel 1978, di Orientalismo di Edward Said, considerata l'opera fondatrice degli studi postcoloniali, per rintracciare una serie di "precursori" francofoni, tra i quali ovviamente spicca la figura dello psichiatra, intellettuale e rivoluzionario martinicano Frantz Fanon, ma anche figure storiche che non si prestano ad interpretazioni sempliciste, quali Toussaint Louverture, e grandi intellettuali che vengono generalmente collocati prima della "frattura" poststrutturalista, come Roland Barthes, del cui lavoro sulla semiologia vengono riconosciuti i contributi ad una teoria postcoloniale dell'emancipazione. La seconda sezione, "Postcolonialism, Modernity, and French Identities", muove verso una rivisitazione dei più comuni assunti riguardanti l'identità francese, analizzando l'impatto delle letterature del Maghreb e del "pensiero nomadico" sulle nozioni di nazionalismo e di pluralismo culturale, ma anche l'importanza del retroterra culturale algerino su grandi scrittori "francesi" come Hélène Cixous e Jacques Derrida o l'impatto dell'immigrazione postbellica algerina sulle banlieus. La terza parte, intitolata "Displacing Francophonie: Migration and Transcultural Identities" traccia alcuni profili di una concezione transnazionale e diasporica dell'identità, dai paradossi dell'“eccezionalità" del Québec alle letterature dell'immigrazione, ai fondamentali 
cambiamenti storici e culturali introdotti dalla decolonizzazione e dalla globalizzazione nei rapporti tra le ex-colonie e la "métropole". Infine, la quarta sezione, intitolata "Theorizing the Black Atlantic", prende le mosse dal celebre cronotopo indagato da Paul Gilroy e analizza le complesse relazioni che legano le Antille francofone, l'Africa e l'Europa in quello spazio plurale e transculturale che fu un tempo lo spazio della "tratta" degli schiavi verso le Americhe, muovendosi lungo linee che formano intrecci complessi ed allontanandosi dal modello centro-periferia che reggeva la dialettica coloniale. Si passa così dallo studio della diaspora haitiana alle intersezioni teoriche tra i concetti di ibridità di Homi Bhabha, inteso come spazio discorsivo che genera la possibilità di configurare la differenza, e quello più radicale di creolizzazione di Édouard Glissant come "altro del pensiero", generando un incontro esplicativo tra due concetti che segnano una svolta nel progetto teorico postcoloniale. A questi temi viene accostata una riflessione sull'importanza dei modelli teoretici africani e sulla loro influenza sia sul postcolonialismo che sulla francofonia. Il volume è concluso da un articolo di Françoise Lionnet che utilizza il prisma del genere per illuminare il modo in cui la differenza, nelle sue molteplici forme, compone la forma e la sostanza del campo postcoloniale francofono.

4 Il futuro del postcolonialismo e della francofonia, suggerisce a più riprese questa importante collettanea di studi, dipende in larga misura dalle rispettive potenzialità interdisciplinari e comparative. La divisione accademica in dipartimenti basati sulle letterature e le lingue nazionali non riflette più le realtà geopolitiche e culturali, basate su circuiti di scambi e di comunicazione transnazionali e globali, ed i termini stessi di "francofonia" e "postcolonialismo" hanno ormai chiaramente rivelato i loro limiti. Proprio le loro tensioni e contraddizioni interne ne rivelano le potenzialità di apertura e di reciproco attraversamento di confini. Se da una parte il postcolonialismo dovrà prestare maggiore attenzione alle specificità dei testi e dei contesti di produzione, nonché alle relazioni di potere che li sottendono ed al peso di una mediazione fondata quasi esclusivamente sulla traduzione in lingua inglese, dall'altra gli studi francofoni dovranno beneficiare dell'apporto di critici come Bhabha e Spivak, spingendo la Francia a riconsiderare gli esiti della propria storia coloniale, le sue ripercussioni sul presente e la sua ideologia universalista ed assimilazionista. La prospettiva postcoloniale mette seriamente in crisi una visione della "francité" naturalizzata ed omogeneizzata, creata storicamente dall'opposizione ad un'alterità costruita ed autoconsolidante.

Queste sono solo alcune delle feconde prospettive che emergono da questo volume, che meriterebbe un'attenzione ed un'analisi ben più estese ed approfondite e che si pone come un lavoro seminale che senz'altro stimolerà, nei prossimi anni, ulteriori ed innovativi approcci nei confronti delle letterature francofone postcoloniali. 